infants to detect squint and refractive errors. Trans Ophthalmol Soc NZ 1983;35:43-9.

19. Molteno AC, Sanderson GF, Hoare-Nairne J. Clinical experience with the Otago photoscreener. Aust NZ J Ophthalmol 1985;13:49-58.

20. Molteno AC, Hoare-Nairne J, Sanderson GF, Peart DA, Hodgkinson IJ. Reliability of the Otago photoscreener: a study of a thousand cases. Aust NZ J Ophthalmol 1994;21:257-65.

21. Kennedy RA, Sheps SB. A comparison of photoscreening techniques for amblyogenic factors in children. Can J Ophthalmol 1989;24:259-64.

22. Freedman HL, Preston KL. Polaroid photoscreening for amblyogenic factors: an improved methodology. Ophthalmology 1992;99:1785-95.

23. Hope C, Roulston J, Hoey C, Wong A, Clover G. Community photoscreening of six to nine month old infants for amblyogenic factors. Aust NZ J Ophthalmol 1994;22:193-202.

Sir,

\section{Psychogenic Erectile Dysfunction Complicating Ophthalmic Surgery}

Male sexual impotence associated with ocular disease or therapy is not frequently encountered in ophthalmic practice. Erectile dysfunction (ED) is now the preferred term for this condition and is defined as the inability of the male to achieve an erect penis as part of the overall multifaceted process of male sexual function'. We report a case of psychogenic erectile dysfunction resulting from cataract extraction. To our knowledge this is the first report of ED complicating ophthalmic surgery. The causes of diminished erectile ability in patients with ocular disease are discussed.

\section{Case Report}

A 53-year-old man was referred to the ophthalmic outpatient department in 1987 because of a 2 year history of gradual and painless deterioration of vision in both eyes. He was systemically fit and well and was receiving no medications. Examination revealed a visual acuity of $6 / 18$ in the right eye and 6/24 in the left eye and significant bilateral lens opacities. No other ocular pathology was noted.

Left extracapsular cataract extraction (ECCE) with posterior chamber intraocular lens (PCIOL) implantation was performed in 1988. This was complicated in the post-operative period by displacement of the PCIOL. The intraocular lens was removed in 1992 and replaced with an anterior chamber IOL. Unfortunately post-operative astigmatism $\left(+8.0\right.$ dioptres at $\left.12^{\circ}\right)$ necessitated refractive surgery in the form of compression sutures. Following left YAG posterior capsulotomy a best corrected final visual acuity of $6 / 5$ was achieved in this eye.

Right ECCE and PCIOL implantation was successfully undertaken in 1990 resulting in a best corrected final visual acuity of 6/5. The patient was delighted with the visual result in both eyes.
The patient came for final follow-up to the outpatient department in 1995 . He had no visual complaints but did report post-coital retro-orbital pain bilaterally and said he was afraid to partake in sexual relations with his partner in case his eyes would 'burst open'. Visual acuity was $6 / 5$ bilaterally. Anterior segment findings were consistent with previous surgical procedures, there was no evidence of narrow angles on gonioscopy and the intraocular pressures were normal. No fundus abnormalities were noted.

Psychosexual assessment revealed that the patient had been suffering from diminished erectile ability for the previous 3 years and loss of orgasmic pleasure on ejaculation. Sexual intercourse with his wife is only possible when he is sure that she is comfortable as she suffers from severe cervical spondylitis. $\mathrm{He}$ still achieved very good early morning erections and nocturnal emissions. Interestingly, as a teenager he had been told at school that too much sex would make him blind and he assumed that this was the cause of his cataracts. The following investigations were normal: serum prolactin, serum cholesterol, serum triglycerides, serum HDL cholesterol, blood glucose and thyroid function tests. Testosterone was slightly low at $10 \mathrm{nmol} / \mathrm{l}$.

\section{Comment}

ED has traditionally been classified as either psychogenic or organic. However, it is now recognised that in many cases both psychological and medical factors play a role and are interactively additive. ${ }^{1}$ It is therefore important to identify all aetiopathogenic factors in cases of ED if the condition is to be treated appropriately.

The most reliable discriminators between primarily functional and primarily biogenic ED include nocturnal penile tumescence and the presence and rigidity of morning erections. ${ }^{2}$ Sleep erections reflect the potential of the penis to become rigid unencumbered by psychological factors. The patient reported here experienced both nocturnal emissions and morning erections.

Acute attacks of angle closure glaucoma provoked by sexual intercourse have been described. ${ }^{3}$ However, the patient described here had deep anterior chambers and wide-open angles.

We believe the retro-orbital pain reported by our patient was psychosomatic in origin, reflecting his concern over his wife's comfort during intercourse. These symptoms in turn resulted in anxiety regarding the health of his eyes following the multiple ophthalmic procedures he had undergone, and the fear that his eyes might 'burst open' during lovemaking. This sequence of events resulted in ED.

This case represents the first report of psychogenic ED complicating ophthalmic surgery. The organic 
causes of male impotence that might be encountered in an ophthalmic practice may be divided into disease-related and iatrogenic. Pathologies responsible for ocular disease and male sexual dysfunction include multiple sclerosis, diabetes mellitus with autonomic neuropathy, generalised atheromatous disease, hypothyroidism and hyperthyroidism. ${ }^{4}$ Intracranial lesions such as pituitary tumours with endocrine dysfunction and temporal lobe neoplasms may cause erectile failure and field loss. ${ }^{3}$ One case of male sexual impotence in association with tuberculoma of the optic chiasm has also been described. ${ }^{5}$ Iatrogenic ED has been reported with the use of topical timolol. ${ }^{6}$

The possibility of a neurological, vascular or endocrine aetiology should be suspected in all cases of ED. In the absence of an organic cause patients should be referred for psychosexual assessment and undergo psychotherapy. The aim of this treatment is to transform the psychosomatic symptom of impotence into a cognitive and emotional experience. As a result of this approach our patient is gaining insight into the source of his problem and his sexual function is improving.

S. Beatty, FRCOphth

Birmingham and Midland Eye Centre

Dudley Road

Birmingham B18 7QH

UK
J. Dewsbury, MFFP, Memb Inst of Psychosexual Med

City Hospital

Dudley Road

Birmingham B18 7QH

UK

N. Kumar, FRCOphth

Selly Oak Hospital

Selly Oak

Birmingham

UK

\section{References}

1. Althof SE, Seftel AD. The evaluation and management of erectile dysfunction. Psychiatr Clin North Am 1995;18:171-92.

2. Speckens AEM, Hengeveld MW, Lycklama GAB, van Hemert AM, Hawton KE. Discrimination between psychogenic and organic erectile dysfunction. J Psychosom Res 1993;37:135-45.

3. Markovits AS. Ophthalmodynia hypertonica copulationi: a new syndrome? Can J Ophthalmol 1974;9:484-5.

4. Richardson MD. Medical causes of male sexual dysfunction. Med J Aust 1991;155:29-33.

5. Iraci G, Giordano R, Geroza M, Pardatscher K, Tomazzoli L. Tuberculoma of the anterior optic pathways. J Neurosurg 1980;52:129-33.

6. Wilson RP, Spaeth GL, Poryzees E. The place of timolol in the practice of ophthalmology. Ophthalmology 1980;87:451-4. 